\title{
Antimicrobial Effect of Calcium Chloride Alone and Combined with Lactic Acid Injected into Chicken Breast Meat
}

\author{
Amali U. Alahakoon ${ }^{1}$, Dinesh D. Jayasena ${ }^{1}$, Samooel Jung ${ }^{1}$, Hyun Joo Kim, \\ Sun Hyo Kim${ }^{1}$, and Cheorun Jo* \\ Department of Agricultural Biotechnology, Center for Food and Bioconvergence, and Research Institute \\ of Agriculture and Life Science, Seoul National University, Seoul 151-921, Korea \\ ${ }^{I}$ Department of Animal Science and Biotechnology, Chungnam National University, Daejeon 305-764, Korea
}

\begin{abstract}
Chicken breast meat was injected with calcium chloride alone and in combination with lactic acid $(0.01 \%$ and $0.002 \%$, respectively). The inhibitory effects of the treatments on microbial growth were determined in the injected chicken breast meat stored at $4{ }^{\circ} \mathrm{C}$ under aerobic packaging condition for 0,3 , and $7 \mathrm{~d}$. Calcium chloride combined with $0.002 \%$ and $0.01 \%$ lactic acid reduced microbial counts by 0.14 and $1.08 \mathrm{Log} \mathrm{CFU} / \mathrm{g}$, respectively, however, calcium chloride alone was unable to inhibit microbial growth. Calcium chloride combined with $0.01 \%$ lactic acid was the most effective antimicrobial treatment and resulted in the highest initial redness value. Calcium chloride alone and combined with lactic acid suppressed changes in $\mathrm{pH}$ and the Hunter color values during storage. However, injection of calcium chloride and lactic acid had adverse effects on lipid oxidation and sensory characteristics. The higher TBARS values were observed in samples treated with calcium chloride and lactic acid when compared to control over the storage period. Addition of calcium chloride and lactic acid resulted in lower sensory scores for parameters tested, except odor and color, compared to control samples. Therefore, the formulation should be improved in order to overcome such defects prior to industrial application.
\end{abstract}

Key words: calcium chloride, lactic acid, injection, breast meat, shelf life

\section{Introduction}

There are ever increasing concerns on the safety of poultry meat due to its inherent association with foodborne pathogens. During poultry processing, cross-contamination and a subsequent increase in the bacterial load of the final product may occur (Luber and Reiher, 2009). Therefore, reducing the microbial load in the final product would extend its shelf life and be beneficial for processors, retailers, and consumers.

The above-mentioned concerns have led to the development and application of several thermal and non-thermal food preservation technologies, alone or in combination, for many years in order to control spoilage and pathogenic microorganisms (Jayasena and Jo, 2013). Marination as a method of value addition has become an integral part of the meat industry due to the increasing de-

*Corresponding author: Cheorun Jo, Department of Agricultural Biotechnology, Seoul National University, Seoul 151-921, Korea. Tel: 82-2-880-4804; Fax: 82-2-873-2271, E-mail: cheorun@snu.ac.kr mands of consumers for further processed, ready-to-eat, and convenient foods (Alvarado and Mckee, 2007). Therefore, the use of marinades to improve the microbiological and technological qualities of meat products has been proven as an effective processing and preservation method over the past 30 years (Jensen et al., 2003).

The salts of lactic acid and various other weak acids are used in enhancement solutions as effective microbial inhibitors (Doores, 2005). Several studies have documented the efficacy of organic acids in the reduction of enteric pathogens on carcasses and derived cuts (Bosilevac et al., 2006; González-Fandos et al., 2009). Lactic acid is a nontoxic, weak acid naturally produced in meat and meat products and offers the possibility of reducing contamination of meat and meat products (Cardenas et al., 2008). Hence, it is a generally regarded as safe antimicrobial agent that is commonly used in meat and meat products for decontamination (Kotula and Thelappurate, 1994).

Traditionally, acidic marinades were used to improve the flavor and texture of prepared meat products during storage (Kijowski and Mast, 1993). Injection of marinades allows more rapid diffusion of the acid into the muscle 
and results in a rapid decrease in mechanical strength and increase in tenderness (Eilers et al., 1994). However, acidic marinades have recently become more popular as antimicrobial ingredients. As reviewed by Doores (2005), lactic acid was able to inhibit the growth of many types of food spoilage bacteria, including gram-negative species of the families Enterobacteriaceae and Pseudomonaceae. Moreover, organic acids (acetic, formic, and lactic) improved the shelf life by decreasing microbial loads on meat products (Özdemir et al., 2006). This antimicrobial effect was attributed to both reduction of the $\mathrm{pH}$ below the range required for microbial growth and metabolic inhibition due to undissociated acid molecules (Alvarado and Mckee, 2007). However, the main limitation of using organic acids in meat systems is the discoloration of meat cuts, especially at higher concentrations of organic acids (Kotula and Thelappurate, 1994). Sawyer et al. (2009) demonstrated color stability of meat after incorporation of lactic acid. Therefore, changes in sensory parameters (color and flavor) should be taken into consideration when using acidic marinades.

In addition to acidic marinades, alkali salt phosphate marinade systems increase the water-holding capacity and tenderize the meat. Most recently, treatment with calcium chloride as an alkaline marinade has become a popular method for meat tenderization because of the ease of application and safe nature (Gerelt et al., 2002). Calcium chloride treatment has been applied either to pre- or postrigor muscle tissues as an effective means of improving meat tenderness (Wheeler et al., 1992). In addition to improving the tenderness, the calcium chloride marination technology would improve other economically important traits such as extending color life and inhibiting microbial growth (Lawrence et al., 2003). Furthermore, meat injected with calcium chloride may serve as an additional source of calcium because meat is widely consumed at all ages (Heaney and Barger-Lux, 1991).

Although extensive studies have been conducted on the effects of calcium chloride treatment on texture improvement, little information is available on the effect of such treatment on the microbial inhibition in meat and meat products. However, some sensory properties, e.g., color and flavor, can be altered by this treatment depending on the concentration used (Lansdell et al., 1995). Several studies have shown that calcium chloride conveyed a bitter, metallic, and sour taste to cooked products (Eilers et al., 1994; Morris et al., 1997). Therefore, the concentration of calcium chloride should be carefully selected (Lansdell et al., 1995). In addition, because the dietary intake of lactic acid and calcium chloride is not limited, their use in meat products is favorable (Mani-Lopez et al., 2012).

Chicken breast is one of the most popular and easily preparable type of meat used for grilling and can absorb greater amounts of marinade compared to the thigh. Hence, chicken breast is widely used in the "seasoned" meat industry all over the world with differently modified recipes. However, quality attributes of marinated meat products could be deteriorated due to the microbial growth and it cause a public health hazard along with economic loss to the industry. The recent focus is to use different antimicrobial hurdles together in the food preservation such as low and high temperature, acidity, antimicrobial compounds, and thermal and non-thermal sterilization. Therefore, an effective combination of different antimicrobial hurdles in meat products can work in synergy and thereby provide a good antimicrobial effect.

Our objective in this study was to determine the inhibitory effects of calcium chloride alone and in combination with lactic acid on microbial growth upon injection into chicken meat packaged under aerobic conditions and stored at $4^{\circ} \mathrm{C}$.

\section{Materials and Methods}

\section{Sample preparation}

All necessary ingredients for the production of different marinades and the fresh skinless chicken breast meat used in this study were obtained from a local market (Daejeon, Korea). The chicken breast meat samples were immediately transported to the laboratory in a polystyrene box containing ice and stored in refrigerator at $4^{\circ} \mathrm{C}$ for less than $12 \mathrm{~h}$ until further use.

\section{Marinades}

The basal marinade was prepared by mixing corn syrup, sugar, soy sauce, onion, welsh onion, pears, sesame oil, garlic, table salt, monosodium glutamate, sesame, caramel, and ginger with water. Four treatment marinades were prepared: i) Control: basal marinade with no additive, ii) $3 \%$ of calcium chloride (ES Food Industry, Korea): basal marinade with $3 \%$ calcium chloride, iii) $3 \%$ of calcium chloride with $0.002 \%$ lactic acid: basal marinade with $3 \%$ of calcium chloride and $0.002 \%$ lactic acid and iv) $3 \%$ of calcium chloride with lactic acid at $0.01 \%$ : basal marinade with $3 \%$ of calcium chloride and $0.01 \%$ lactic acid. All marinades were prepared in the same day of the experiment and held at $4^{\circ} \mathrm{C}$ until required and the preliminary trials were conducted to determine the appropriate 
marinade formulation and the cooking conditions to be used in this study.

\section{Marination and storage of samples}

The breast meat samples were randomly assigned to the control and three treatments separately. Prior to the marination, the breast meat samples were weighed, and then injected with their respective marinades $(15 \% \mathrm{w} / \mathrm{w})$ using a single-needle injector (Doo Won Meditec Co. Ltd., Korea). The marinades were pumped deeply into the meat pieces in every side in order to ensure the homogenous distribution of marinade ingredients. Each treated sample was subsequently divided into small portions (approximately $25 \mathrm{~g}$ ), aerobically packaged in oxygen-permeable polyethylene bags and stored at $4^{\circ} \mathrm{C}$ until analysis at 0,3 , and $7 \mathrm{~d}$.

\section{Microbiological analysis}

Microbial analysis was carried out initially after injection of the marinades and at 0,3 and $7 \mathrm{~d}$ of storage at $4^{\circ} \mathrm{C}$. Each sample ( $5 \mathrm{~g}$ ) was cut into small pieces and homogenized for $2 \mathrm{~min}$ in a sterile stomacher bag (bag mixer 400; Interscience Co., France) containing $45 \mathrm{~mL}$ of sterile saline $(0.85 \%)$. Then, those were serially diluted in sterile saline $(0.85 \%)$, and each diluent $(0.1 \mathrm{~mL})$ was spread on respective bacterial media. Plate count agar and eosine methylene blue agar (Difco Laboratories, USA) were used for the determination of total bacterial flora and coliforms, respectively. The plates were incubated at $37^{\circ} \mathrm{C}$ for $48 \mathrm{~h}$, and the microbial counts were expressed as Log CFU/g.

\section{pH measurement}

Each sample $(1 \mathrm{~g})$ was homogenized with $9 \mathrm{~mL}$ of distilled water using a mechanical homogenizer (Ika Laboratory Equipment, Korea) and filtered (Whatman No.4, GE Healthcare UK Ltd., UK). The $\mathrm{pH}$ value of the filtrate was measured using an electronic $\mathrm{pH}$ meter (Mettler Toledo Process Analytics, USA) at room temperature, which was initially calibrated using standard phosphate buffers. The electrode was washed thoroughly with distilled water between measurements. The mean value of three repeated measurements from each sample was used.

\section{Instrumental color measurement}

The surface color measurements (CIE L*, a*, and $b^{*}$ values representing lightness, redness and yellowness, respectively) of the marinated chicken breast meat samples were evaluated immediately after the sampling and during the storage period using a colorimeter (Spectropho- tometer, CR-300, Minolta Inc., Japan) which was calibrated against a black and a white reference tiles. Measurements of $L^{*}, a^{*}$ and $b^{*}$ values were taken at three different locations of each of the three replicates from each treatment.

\section{Lipid oxidation}

Lipid oxidation was measured at 0,3 and $7 \mathrm{~d}$ as 2thiobarbituric acid reactive substance (TBARS) value of each sample (Jung et al., 2011). Nine $\mathrm{mL}$ of distilled water and $50 \mathrm{~mL}$ BHT $(7.2 \%$ in ethanol) were added to each meat sample $(3 \mathrm{~g})$. The mixture was then homogenized (Ika Laboratory Equipment, Korea) at 16,000 rpm for $20 \mathrm{~s}$. The homogenate $(1 \mathrm{~mL})$ was transferred to a test tube and then mixed with $2 \mathrm{~mL}$ of thiobarburic acid (TBA)/trichloroacetic acid (TCA) solution (20 mM TBA in $15 \% \mathrm{TCA})$. After that, the test tubes were heated in a water bath at $90^{\circ} \mathrm{C}$ for $15 \mathrm{~min}$, cooled in cold water, and centrifuged (Union 32R, Hanil Co. Ltd., Korea) at 3,000 rpm for $10 \mathrm{~min}$. The absorbance of the supernatant was measured at $532 \mathrm{~nm}$ with a spectrophotometer (DU 530; Beckman Instruments Inc., USA). The amount of malondialdehyde was calculated using a standard curve prepared from tetraethoxypropane, and the TBARS value was reported as $\mathrm{mg}$ malondialdehyde/kg meat.

\section{Sensory evaluation}

In the present study, the marinated chicken meat samples were evaluated for their sensory qualities at the first day of sampling as three repeated sessions. The samples $(2.0 \times 3.0 \times 1.5 \mathrm{~cm})$ were pan-fried in an electric grill with double pans (Nova EMG-553, 1400 W, Evergreen, Korea) for $4 \mathrm{~min}$ to achieve a core temperature of approximately $72^{\circ} \mathrm{C}$ as measured by a digital thermometer (YF-160Atype-K, YFE, Taiwan).

Immediately after the preparation of the cooked products, each sample was placed in a white plastic tray with randomly coded 3 digit numbers and provided for the evaluation. Water was provided between the samples to cleanse the oral cavity. The cooked samples were evaluated for color, odor, flavor, taste, tenderness and overall acceptability by seven semi-trained panelists who have experience in sensory evaluation of chicken meat for more than one year. The panel was asked to indicate whether the products had an acceptable or unacceptable (deviating) taste, flavor, and odor. A 9-point hedonic scale was used ( $9=$ like extremely, 5=like moderately, $1=$ dislike extremely) in this study. 


\section{Statistical analysis}

The data of this experiment was analyzed using a oneway analysis of variance by the procedure of general linear model using SAS program (SAS version 9.3, SAS Institute, USA). The whole experimental procedures were triplicated. The differences among the mean values were compared using Duncan's multiple range test at a confidence level of $p<0.05$. The mean values and standard errors of the means are reported.

\section{Results and Discussion}

\section{Microbiological analysis}

The additive effects of calcium chloride alone and in combination with lactic acid on the growth of total aerobic bacteria in chicken breast meat are shown in Table 1. Treatment of samples with calcium chloride combined with $0.002 \%$ or $0.01 \%$ lactic acid resulted in significantly lower initial microbial counts than those observed with other treatments. Compared to control samples, the treated samples showed a reduction in microbial counts by 0.14 and $1.08 \mathrm{Log} \mathrm{CFU} / \mathrm{g}$, respectively. No significant difference in microbial counts was observed between control and breast samples treated with calcium chloride at $0 \mathrm{~d}$. However, calcium chloride treatment significantly lowered the growth of microorganisms during the rest of the storage period. Calcium chloride combined with $0.01 \%$ lactic acid showed the greatest inhibitory effect throughout the storage period. However, calcium chloride alone was unable to inhibit microbial growth to the extent that combined treatments did. Significant differences were found between total aerobic counts of treated samples and untreated control samples at $3 \mathrm{~d}$ and $7 \mathrm{~d}$ of storage; by $3 \mathrm{~d}$, the microbial counts of control samples were higher than

Table 1. Total aerobic bacterial counts (Log CFU/g) of chicken breast meat samples treated with calcium chloride and lactic acid

\begin{tabular}{ccccc}
\hline \hline \multirow{2}{*}{ Treatment } & \multicolumn{3}{c}{ Storage period (d) } & \multirow{2}{*}{ SEM $^{1)}$} \\
\cline { 2 - 4 } & 0 & 3 & 7 & \\
\hline Control & $4.75^{\mathrm{az}}$ & $7.18^{\mathrm{ay}}$ & $9.52^{\mathrm{ax}}$ & 0.09 \\
$3 \% \mathrm{CC}$ & $4.72^{\mathrm{az}}$ & $5.91^{\mathrm{by}}$ & $6.94^{\mathrm{bx}}$ & 0.02 \\
$3 \% \mathrm{CC}+0.002 \% \mathrm{LA}$ & $4.61^{\mathrm{bz}}$ & $5.52^{\mathrm{cy}}$ & $6.03^{\mathrm{cx}}$ & 0.03 \\
$3 \% \mathrm{CC}+0.01 \% \mathrm{LA}$ & $3.67^{\mathrm{cz}}$ & $4.56^{\mathrm{dy}}$ & $5.26^{\mathrm{dx}}$ & 0.10 \\
$\mathrm{SEM}^{2)}$ & 0.03 & 0.02 & 0.12 & \\
\hline
\end{tabular}

$\mathrm{CC}$, calcium chloride; LA, lactic acid

${ }^{1)}$ Standard errors of the mean $(n=9)^{2)} n=12$

${ }^{\mathrm{a}-\mathrm{d}}$ Values with different letters within the same column differ significantly $(p<0.05)$.

${ }^{x-z}$ Values with different letters within the same row differ significantly $(p<0.05)$.
$7 \mathrm{Log}$ CFU/g. However, even at the end of the storage period, the microbial counts of treated samples had not reached 7 Log CFU/g. Nevertheless, the microbial counts in breast meat samples increased over the storage period, regardless of the treatment.

In this study, the combination of calcium chloride and lactic acid was the most effective antimicrobial treatment. Furthermore, increasing the lactic acid concentration was beneficial with regard to microbial reduction because combined treatment with $0.01 \%$ lactic acid had a greater inhibitory effect than combined treatment with $0.002 \%$ lactic acid. When the acidity in marinade increases, diffusion across membranes and into the cytoplasm of microbes may increase, too. In general, microorganisms have specific $\mathrm{pH}$ requirements for growth and a $\mathrm{pH}$ range within which their growth is possible. Thus, even a small decrease in the $\mathrm{pH}$ by organic acids is sufficient to prevent the growth of many bacteria (Stratford and Anslow, 1998). In previous studies, lactic acid had been shown to possess antimicrobial activity against many pathogenic organisms, e.g., Clostridium botulinum, because of its ability to reduce the $\mathrm{pH}$, exert feedback inhibition, and interfere with the proton transfer across cell membranes (Davidson et al., 2005; Doores, 2005). Furthermore, the initial total aerobic count of chicken breast dipped in lactic acid decreased by 0.53 to $2.36 \mathrm{Log}$ CFU/g (Anang et al., 2010). Similarly, the antimicrobial effect of calcium chloride combined with lactic acid was revealed by Eilers et al. (1994), who observed a significant reduction in microbial growth, while improvements in tenderness were maintained in hot bonedround cuts.

However, the antibacterial effects of organic acids depend on two factors, i.e., $\mathrm{pH}$ and degree of dissociation of the acid. In addition, it is known that the antibacterial effect of lactic acid varies depending on the concentration of the acid, temperature of the solution, and method and time of application (Tamblyn and Conner, 1997).

In addition, several agents in salt solutions such as calcium chloride can endow bacterial growth inhibition. Elevated osmolality due to salt addition may trigger the osmoregulatory process causing increased maintenance metabolism and leading to reduced bacterial growth (Yaganza et al., 2009). Our study confirmed the findings of Yaganza et al. (2009) who reported that the acidity or alkalinity of the medium caused by addition of salts could have adverse effects on bacterial growth. Extreme $\mathrm{pH}$ conditions can lead to the denaturation of proteins, including enzymes present on the cell surface, depolarization of transport systems for essential ions and nutrients, modification of 
the cytoplasmic $\mathrm{pH}$, and DNA damage (Gould and Russell, 1991).

However, in our study, the shelf-life of chicken breast meat could be extended at least to $7 \mathrm{~d}$ by injecting a combination of calcium chloride and lactic, whereas the shelflife of control samples and samples treated with calcium chloride alone was $<3$ and $7 \mathrm{~d}$, respectively.

\section{pH value}

Marination with calcium chloride alone and combined with lactic acid had significant effects on the initial $\mathrm{pH}$ values of chicken breast meat samples (Table 2). The $\mathrm{pH}$ values decreased immediately following treatment with calcium chloride alone and in combination with $0.002 \%$ and $0.01 \%$ lactic acid by $0.79,0.71$, and 0.71 , respectively, in comparison to control samples. The highest $\mathrm{pH}$ values were observed in control samples throughout the storage period, whereas no significant differences in the $\mathrm{pH}$ values were found among the treated samples at 0 and $3 \mathrm{~d}$ of storage; however, significant differences were found at 7 $\mathrm{d}$. The $\mathrm{pH}$ value of the control samples increased significantly during storage. However, there were no significant changes in the $\mathrm{pH}$ between samples treated with calcium chloride alone and combined with $0.002 \%$ lactic acid up to $7 \mathrm{~d}$. A slight change in the $\mathrm{pH}$ was observed in samples treated with calcium chloride combined with $0.01 \%$ lactic acid, which was reversed by the end of the storage period. Therefore, treatment with calcium chloride and lactic acid stabilized the $\mathrm{pH}$ value in injected chicken breast meat.

The increase in the $\mathrm{pH}$ during the storage period could be attributed to accumulation of ammonia by bacteria (Gill, 1983). Moreover, the initial $\mathrm{pH}$ reduction following combined treatments could be explained by the buffering capacity of acidulates, which released protons, resulting in a smaller impact on the $\mathrm{pH}$ of the media (Thomas et

Table 2. pH changes in chicken breast meat samples treated with calcium chloride and lactic acid

\begin{tabular}{ccccc}
\hline \hline \multirow{2}{*}{ Treatment } & \multicolumn{3}{c}{ Storage period (d) } & \multirow{2}{*}{ SEM $^{1)}$} \\
\cline { 2 - 4 } & 0 & 3 & 7 & \\
\hline Control & $6.41^{\text {ay }}$ & $6.39^{\text {ay }}$ & $6.73^{\mathrm{ax}}$ & 0.03 \\
$3 \% \mathrm{CC}$ & $5.62^{\mathrm{b}}$ & $5.56^{\mathrm{b}}$ & $5.72^{\mathrm{b}}$ & 0.08 \\
$3 \% \mathrm{CC}+0.002 \% \mathrm{LA}$ & $5.70^{\mathrm{b}}$ & $5.43^{\mathrm{b}}$ & $5.42^{\mathrm{c}}$ & 0.03 \\
$3 \% \mathrm{CC}+0.01 \% \mathrm{LA}$ & $5.70^{\mathrm{bx}}$ & $5.55^{\text {by }}$ & $5.65^{\mathrm{bx}}$ & 0.05 \\
SEM $^{2)}$ & 0.03 & 0.05 & 0.07 & \\
\hline
\end{tabular}

CC, calcium chloride; LA, lactic acid

${ }^{1)}$ Standard errors of the mean $(n=9)^{2)} \mathrm{n}=12$

${ }^{\mathrm{a}-\mathrm{c}}$ Values with different letters within the same column differ significantly $(p<0.05)$.

${ }^{x, y}$ Values with different letters within the same row differ significantly $(p<0.05)$. al., 2002). In general, post-mortem $\mathrm{pH}$ values of avian muscles decrease very rapidly from near neutrality to about 5.6 to 5.8 within 6 to 8 h (Stewart et al., 1984). Because the increase in cytosolic calcium is a main determinant of the onset of rigor mortis, one would suppose that the addition of calcium would prompt the process and lower the $\mathrm{pH}$ of calcium-treated muscles (Young and Lyon, 1997). However, the initial $\mathrm{pH}$ values did not decrease significantly in the present study. These results were in agreement with those of another study that showed that the addition of lactic acid to meat systems such as pork and beef resulted in lower initial $\mathrm{pH}$ values and reduced the post enhancement muscle pH (Aktas et al., 2003).

\section{Instrumental color value}

The instrumental color values of the injected chicken breast meat samples indicated that the highest a* value was observed in samples treated with calcium chloride combined with $0.01 \%$ lactic acid at $0 \mathrm{~d}(p<0.05$; Table 3$)$. However, no significant changes were observed among the treatments during the storage period.

It has been shown that lactic acid has greater affinity for deoxymyoglobin than oxymyoglobin of normal-pH meat, which leads to a steady, unbloomed color with low concentration of lactic acid. This is caused by the ability of lactic acid to change the oxygen binding properties of myoglobin (Giardina et al., 1996). Moreover, Kim et al. (2006) demonstrated that injecting normal-pH beef strip loins with lactic acid caused regeneration of the reduced form of nicotinamide adenine dinucleotide (NADH) via increased lactate dehydrogenase activity; the increase in NADH production resulted in the reduction of metmyoglobin. Sawyer et al. (2009) more recently noted positive effects of lactic acid on the improvement of instrumental and subjective measures of the fresh color of beef. Similar results with regard to the color enhancement through lactic acid were obtained by several other authors, which are in agreement with our results (Kim et al., 2006).

No significant changes in the $\mathrm{L}^{*}$ value were observed among the treated samples throughout the storage period (Table 3). Significantly higher $L^{*}$ values compared to control samples were noted in treated samples at $3 \mathrm{~d}$ of storage. Whereas no changes in the $\mathrm{L}^{*}$ value were observed in samples subjected to combined treatments over the storage period, that of samples treated with calcium chloride alone did change. Moreover, there was no significant difference in the $b^{*}$ values between the treatment groups (Table 3). However, a significant increase in the $b^{*}$ value was detected in samples injected with calcium chloride 
Table 3. Hunter color values of chicken breast meat samples treated with calcium chloride and lactic acid

\begin{tabular}{|c|c|c|c|c|c|}
\hline \multirow{2}{*}{ Hunter color } & \multirow{2}{*}{ Treatment } & \multicolumn{3}{|c|}{ Storage period $(\mathrm{d})$} & \multirow{2}{*}{ SEM $^{1)}$} \\
\hline & & 0 & 3 & 7 & \\
\hline \multirow{5}{*}{$\mathrm{L}^{*}$} & Control & 56.64 & $56.51^{b}$ & 56.57 & 0.82 \\
\hline & $3 \% \mathrm{CC}$ & $59.44^{y}$ & $63.01^{\text {ax }}$ & $63.68^{x}$ & 0.93 \\
\hline & $3 \% \mathrm{CC}+0.002 \% \mathrm{LA}$ & 61.57 & $65.00^{\mathrm{a}}$ & 64.17 & 2.53 \\
\hline & $3 \% \mathrm{CC}+0.01 \% \mathrm{LA}$ & 56.00 & $61.73^{\mathrm{a}}$ & 62.89 & 1.66 \\
\hline & $\mathrm{SEM}^{2)}$ & 1.61 & 1.22 & 1.99 & \\
\hline \multirow{5}{*}{$a^{*}$} & Control & $2.26^{\mathrm{ab}}$ & 3.01 & 3.31 & 0.56 \\
\hline & $3 \% \mathrm{CC}$ & $3.46^{\mathrm{ab}}$ & 3.09 & 2.81 & 0.34 \\
\hline & $3 \% \mathrm{CC}+0.002 \% \mathrm{LA}$ & $1.96^{\mathrm{b}}$ & 2.15 & 2.06 & 0.81 \\
\hline & $3 \% \mathrm{CC}+0.01 \% \mathrm{LA}$ & $3.72^{\mathrm{a}}$ & 4.17 & 3.63 & 0.40 \\
\hline & $\mathrm{SEM}^{2)}$ & 0.37 & 0.47 & 0.76 & \\
\hline \multirow{5}{*}{$b^{*}$} & Control & 12.84 & 13.48 & 13.25 & 0.69 \\
\hline & $3 \% \mathrm{CC}$ & 13.59 & 13.88 & 14.85 & 0.60 \\
\hline & $3 \% \mathrm{CC}+0.002 \% \mathrm{LA}$ & 14.17 & 14.62 & 16.58 & 1.35 \\
\hline & $3 \% \mathrm{CC}+0.01 \% \mathrm{LA}$ & $12.98^{y}$ & $14.59^{x y}$ & $15.70^{\mathrm{x}}$ & 0.48 \\
\hline & $\mathrm{SEM}^{2)}$ & 0.74 & 0.37 & 1.22 & \\
\hline
\end{tabular}

CC, calcium chloride; LA, lactic acid

${ }^{1)}$ Standard errors of the mean $(n=9){ }^{2} n=12$

${ }^{\mathrm{a}, \mathrm{b}}$ Values with different letters within the same column and same color value differ significantly $(p<0.05)$.

${ }^{\mathrm{x}, \mathrm{y}}$ Values with different letters within the same row differ significantly $(p<0.05)$.

combined with $0.01 \%$ lactic acid over the storage period, whereas those of the other treatment groups remained unchanged.

Lansdell et al. (1995) reported similar results, i.e., beef samples treated with lactic acid had higher $\mathrm{L}^{*}$ values compared to control samples. On the other hand, our results were in good agreement with the findings of Perez et al. (1998) who reported a higher lightness of calcium chloride-marinated meat samples from chicken, horse, cattle, and rabbit. Furthermore, according to the findings of Aktas and Kaya (2001), the lower pH values of acidtreated samples may have resulted in denaturation of sarcoplasmic and myofibrillar proteins, which may alter their water-binding ability. Therefore, the amount of water dispersed among the muscle fibers could affect the reflectance ability of the meat. The increased lightness caused by calcium chloride treatment was probably due to the more intense disruption of myofibrils because of the activation of calpains by calcium (Aktas and Kaya, 2001).

However, the use of appropriate amounts of lactic acid is important to determine the effect on the fresh and cooked color of meat. Kotula and Thelappurate (1994) reported that lactic acid concentrations of $1.2 \%$ and $1.5 \%$ caused color deterioration in beef samples during display.

\section{TBARS value}

As illustrated in Table 4, there were no differences ( $p>$ 0.05 ) in the initial TBARS values among the treatment groups. At $3 \mathrm{~d}$ of storage, the highest TBARS value was
Table 4. TBARS values (mg malondialdehyde/kg meat) of the injected chicken breast meat added with calcium chloride and lactic acid

\begin{tabular}{ccccc}
\hline \hline \multirow{2}{*}{ Treatment } & \multicolumn{3}{c}{ Storage period (d) } & \multirow{2}{*}{ SEM $^{1)}$} \\
\cline { 2 - 4 } & 0 & 3 & 7 & \\
\hline Control & $0.48^{\mathrm{y}}$ & $0.60^{\mathrm{dx}}$ & $0.52^{\mathrm{cy}}$ & 0.02 \\
$3 \% \mathrm{CC}^{*}$ & $0.41^{\mathrm{y}}$ & $0.78^{\mathrm{cy}}$ & $1.81^{\mathrm{ax}}$ & 0.11 \\
$3 \% \mathrm{CC}+0.002 \% \mathrm{LA}^{* *}$ & $0.45^{\mathrm{y}}$ & $1.17^{\mathrm{bx}}$ & $1.24^{\mathrm{bx}}$ & 0.03 \\
$3 \% \mathrm{CC}+0.01 \% \mathrm{LA}$ & $0.49^{\mathrm{y}}$ & $1.25^{\mathrm{ax}}$ & $1.38^{\mathrm{bx}}$ & 0.10 \\
$\mathrm{SEM}^{2)}$ & 0.02 & 0.02 & 0.13 & \\
\hline
\end{tabular}

TBARS: thiobarbituric acid-reactive substances,

${ }^{*}$ CC: calcium chloride, ${ }^{* *}$ LA: lactic acid.

${ }^{1)}$ Standard errors of the mean $(n=9) .{ }^{2}(n=12)$.

${ }^{\text {a-d }}$ Values with different letters within the same column differ significantly $(p<0.05)$.

${ }^{x, y}$ Values with different letters within the same row differ significantly $(p<0.05)$.

observed in samples treated with calcium chloride combined with $0.01 \%$ lactic acid followed by combination with $0.002 \%$ lactic acid; however, the highest value was found at $7 \mathrm{~d}$ in samples treated with calcium chloride alone followed by the groups of combined treatment. Significantly, higher values were observed in samples treated with calcium chloride and lactic acid in comparison to control samples over the storage period. However, the TBARS values increased over the storage period $(p<0.05)$ in all treatment groups. Therefore, in the present study, calcium chloride alone or in combination with lactic acid was not effective in inhibiting lipid oxidation in meat samples. These data are in agreement with those of Harris 
Table 5. Sensory scores of chicken breast meat samples treated with calcium chloride and lactic acid ${ }^{1)}$

\begin{tabular}{|c|c|c|c|c|c|c|}
\hline Treatment & Color & Odor & Flavor & Taste & Tenderness & Overall acceptability \\
\hline Control & $5.43^{\mathrm{a}}$ & $5.00^{\mathrm{a}}$ & $5.57^{\mathrm{a}}$ & $5.64^{\mathrm{a}}$ & $5.57^{\mathrm{a}}$ & $5.64^{\mathrm{a}}$ \\
\hline $3 \% \mathrm{CC}^{*}$ & $5.07^{\mathrm{ab}}$ & $4.93^{\mathrm{ab}}$ & $3.50^{\mathrm{b}}$ & $3.21^{b}$ & $4.14^{\mathrm{b}}$ & $3.50^{\mathrm{b}}$ \\
\hline $3 \% \mathrm{CC}+0.002 \% \mathrm{LA}^{* *}$ & $5.07^{\mathrm{ab}}$ & $4.50^{\mathrm{ab}}$ & $2.86^{\mathrm{b}}$ & $2.50^{\mathrm{b}}$ & $4.07^{b}$ & $2.64^{b}$ \\
\hline $3 \% \mathrm{CC}+0.01 \% \mathrm{LA}$ & $4.71^{b}$ & $4.36^{\mathrm{b}}$ & $2.93^{\mathrm{b}}$ & $2.64^{\mathrm{b}}$ & $4.00^{\mathrm{b}}$ & $2.71^{b}$ \\
\hline $\mathrm{SEM}^{2)}$ & 0.22 & 0.21 & 0.34 & 0.30 & 0.25 & 0.30 \\
\hline
\end{tabular}

$*$ CC: calcium chloride, $* *$ LA: lactic acid.

1) 9 -point hedonic scale (9=like extremely, $5=$ like moderately, $1=$ dislike extremely) used for all sensory parameters.

${ }^{2)}$ Standard errors of the mean $(n=12)$.

${ }^{a, b}$ Values with different letters within the same column differ significantly $(p<0.05)$.

et al. (2001) who reported that calcium chloride marination resulted in increased TBARS values.

\section{Sensory evaluation}

Sensory analysis of the chicken breast meat samples revealed that addition of calcium chloride and lactic acid resulted in lower sensory scores for all parameters, except odor and color, compared to control samples (Table 5). The addition of calcium chloride had no apparent tenderizing effect on cooked meat in comparison to controls. Chicken breast meat injected with calcium chloride alone and combined with $0.002 \%$ lactic acid did not show significant differences in any of the sensory parameters. Moreover, no differences $(p>0.05)$ were observed in flavor, taste, and tenderness among samples treated with calcium chloride alone and combined with $0.01 \%$ lactic acid. The lowest values for color and odor were noted in samples treated with calcium chloride combined with $0.01 \%$ lactic acid $(p<0.05)$, whereas no significant differences were found between samples treated with calcium chloride alone and combined with $0.002 \%$ lactic acid. Panelists rated all samples and the control samples received the highest overall acceptability score followed by samples treated with calcium chloride alone and combined with lactic acid; there were no differences among the treated samples $(p>0.05)$. Negative color attributes were observed when lactic acid was used in marinades, i.e., the meat color changed to a dark gray or gray-brown (Sawyer et al., 2009), which is in agreement with our study. More importantly and similar to our findings, a few studies had shown that calcium solutions conveyed an aftertaste and bitter flavor (Eilers et al., 1994; Perez et al., 1998), whereas Gonzalez et al. (2001) demonstrated that such marinades had no negative effect on meat odor and flavor. The different results obtained by Perez et al. (1998) were probably due to the more efficient incorporation of calcium salt. Therefore, if the concentration and volume of antimicrobial compounds injected into meat could be reduced, negative effects on flavor could be avoided. According to the findings of Morris et al. (1997), injection of calcium chloride and lactic acid increased livery, soured, medicinal and browned aromatics, metallic and astringent mouth feels, salt, and sour and bitter basic tastes and decreased beef/ brothy and serumy/bloody aromatics. Therefore, determining the optimal concentrations of salts and organic acids to ensure better sensory attributes is a challenge and requires further investigations. The use of flavorings and antioxidants in combination with other additives could improve nutritional and sensory attributes; however, further studies are required to obtain such benefits without compromising microbial safety.

In conclusion, combined treatment with calcium chloride and lactic acid could effectively maintain the microbial quality of injected chicken breast meat. Treatment with calcium chloride alone and in combination with lactic acid suppressed changes in $\mathrm{pH}$ and Hunter color values during aerobic storage. However, these treatments had negative effects on lipid oxidation and certain sensory characteristics. These effects need to be minimized or averted by improving the formulation in further experiments.

\section{Acknowledgements}

This work was supported by a grant from the NextGeneration BioGreen 21 Program (No. 0081330), Rural Development Administration, Republic of Korea.

\section{References}

1. Aktas, N. and Kaya, M. (2001) The influence of marinating with weak organic acids and salts on the intramuscular connective tissue and sensory properties of beef. Eur. Food Res. Technol. 213, 88-94.

2. Aktas, N., Aksu, M. I., and Kaya, M. (2003) The effect of organic acid marination on tenderness, cooking loss and bound water content of beef. J. Muscle Foods 14, 181-194.

3. Alvarado, C. and Mckee, S. (2007) Marination to improve 
functional properties and safety of poultry meat. J. Appl. Poult. Res. 16, 113-120.

4. Anang, D. M., Rusul, G., Ling, F. H., and Bhat, R. (2010) Inhibitory effects of lactic acid and lauricidin on spoilage organisms of chicken breast during storage at chilled temperature. Int. J. Food Microbiol. 144, 152-159.

5. Bosilevac, J. M., Nou, X., Barkocy-Gallagher, G. A., Arthur, T. M., and Koohmaraie, M. (2006) Treatments using hot water instead of lactic acid reduce levels of aerobic bacteria and Enterobacteriaceae and reduce the prevalence of Escherichia coli $\mathrm{O} 157: \mathrm{H} 7$ on preevisceration beef carcasses. J. Food Prot. 69, 1808-1813.

6. Cardenas, F. C., Giannuzzi, L., and Zaritzky, N. E. (2008) Mathematical modelling of microbial growth in ground beef from Argentina. Effect of lactic acid addition, temperature and packaging film. Meat Sci. 79, 509-520.

7. Davidson, P. M., Sofos, J. N., and Branen, A. L. (2005) Antimicrobials in Food, 3rd Ed, CRC Press, Boca Raton, FL, pp. 12-17.

8. Doores, S. (2005) Organic acids. In: Antimicrobials in foods. Davidson, P. M., Sofos, J. N., and Branen, A. L. (eds) CRC Press, FL, pp. 91-142.

9. Eilers, J. D., Morgan, J. B., Martin, A. M., Miller, R. K., Hale, D. S., Acuff, G. R., and Savell, J. W. (1994) Evaluation of calcium chloride and lactic acid injection on chemical, microbiological and descriptive attributes of mature cow beef. Meat Sci. 38, 443-451.

10. Gerelt, B., Ikeuchi, Y., Nishiumi, T., and Suzuki, A. (2002) Meat tenderization by calcium chloride after osmotic dehydration. Meat Sci. 60, 237-244.

11. Giardina, B., Ascenzi, P., Clementi, M. E., De Sanctis, G., Rizzi, M., and Coletta, M. (1996) Functional modulation by lactate of myoglobin. A monomeric allosteric hemoprotein. J. Biol. Chem. 271, 16999-17001.

12. Gill, C. O. (1983) Meat spoilage and evaluation of the potential storage life of fresh meat. J. Food Prot. 46, 444-542.

13. Gonzalez, C. B., Salitto, V. A., Carduza, F. J., Pazos, A. A., and Lasta, J. A. (2001) Effect of calcium chloride marination on bovine Cutaneus trunci muscle. Meat Sci. 57, 251-256.

14. González-Fandos, E., Herrera, B., and Maya, N. (2009) Efficacy of citric acid against Listeria monocytogenes attached to poultry skin during refrigerated storage. Int. J. Food Sci. Technol. 44, 262-268.

15. Gould, G. W. and Russel1, N. J. (1991) Sulphite. In: Food preservatives. Russell, N. J. and Gould, G. W. (eds) Blackie and Son Ltd., London, pp. 72-88.

16. Harris, S. E., Huff-Lonergan, E., Lonergan, S. M., Jones, W. R., and Rankins, D. (2001) Antioxidant status affects color stability and tenderness of calcium chloride-injected beef. $J$. Anim. Sci. 79, 666-677.

17. Heaney, R. P. and Barger-Lux, M. J. (1991) Food and Nutrition News. National Livestock \& Meat Board, Chicago, IL, Vol. 63, pp. 2.

18. Jayasena, D. D. and Jo, C. (2013). Essential oils as potential antimicrobial agents in meats and meat products: A review. Trends Food Sci. Tech. 34, 96-108.
19. Jensen, J. M., Robbins, K. L., Ryan, K. J., Homco-Ryan, C., McKeith, F. K., and Brewer, M. S. (2003) Effects of lactic and acetic acid salts on quality characteristics of enhanced pork during retail display. Meat Sci. 63, 501-508.

20. Jung, Y., Jeon, H. J., Jung, S., Choe, J. H., Lee, J. H., Heo, K. N., Kang, B. S., and Jo, C. (2011) Comparison of quality traits of thigh meat from Korean native chickens and broilers. Korean J. Food Sci. An. 31, 684-692.

21. Kijowski, J. and Mast, M. G. (1993) Tenderization of spent fowl drumsticks by marination in weak organic solutions. Int. J. Food Sci. Technol. 28, 337-342.

22. Kim, Y. H., Hunt, M. C., Mancini, R. A., Seyfert, M., Loughin, T. M., Kropf, D. H., and Smith, J. S. (2006) Mechanism for lactate-color stabilization in injection-enhanced beef. J. Agr. Food Chem. 54, 7856-7862.

23. Kotula, K. L. and Thelappurate, R. (1994) Microbiological and sensory attributes of retail cuts of beef treated with acetic and lactic acid solutions. J. Food Prot. 57, 665-670.

24. Lansdell, J. L., Miller, M. F., Wheeler, T. L., Koohmaraie, M., and Ramsey, C. B. (1995) Postmortem injection of calcium chloride effects on beef quality traits. J. Anim. Sci. 73, 17351740.

25. Lawrence, T. E., Dikeman, M. E., Hunt, M. C., Kastner, C. L., and Johnson, D. E. (2003) Effects of calcium salts on beef longissimus quality. Meat Sci. 64, 299-308.

26. Luber, S. and Reiher, M. (2009) Calculated Raman optical activity spectra of 1,6-anhydro-beta-D-glucopyranose. J. Phys. Chem. A. 113, 8268-8277.

27. Mani-Lopex, E., Gracia, H. S., and Lopez-Malo, A. (2012). Organic acids as antimicrobial to control Salmonella in meat and poultry products. Food Res. Int. 45, 713-721.

28. Morris, C. A., Theis, R. L., Miller, R. K., Acuff, G. R., and Savell, J. W. (1997) Improving the flavor of calcium chloride and lactic acid injected mature beef top round steaks. Meat Sci. 45, 531-537.

29. Özdemir, H., Yıldırım, Y., Küplülü, Ö., Koluman, A., Göncüoğlu, M., and İnat, G. (2006) Effects of lactic acid and hot water treatments on Salmonella Typhimurium and Listeria monocytogenes on beef. Food Control 17, 299-303.

30. Perez, M. L., Escalona, H., and Guerrero, I. (1998) Effect of calcium chloride marination on calpain and quality characteristics of meat from chicken, horse, cattle and rabbit. Meat Sci. 48, 125-134.

31. SAS. (2011) SAS/STAT software for PC. Release 9.3, SAS Inst. Inc., Cary, NC, USA.

32. Sawyer, J. T., Apple, J. K., Johnson, Z. B., Baublits, R. T., and Yancey, J. W. (2009) Fresh and cooked color of dark-cutting beef can be altered by post-rigor enhancement with lactic acid. Meat Sci. 83, 263-270.

33. Stewart, M. K., Fletcher, D. L., Hamm, D., and Thomson, J. E. (1984) The effect of hot boning broiler breast muscle on postmortem pH decline. Poultry Sci. 63, 2181-2186.

34. Stratford, M. and Anslow, P. A. (1998) Evidence that sorbic acid does not inhibit yeast as a classic 'weak acid preservative'. Lett. Appl. Microbiol. 27, 203-206.

35. Tamblyn, K. C. and Conner, D. E. (1997) Bactericidal activ- 
ity of organic acids against Salmonella typhimurium attached to broiler chicken skin. J. Food Prot. 60, 629-633.

36. Thomas, K. C., Hynes, S. H., and Ingledew, W. M. (2002) Influence of medium buffering capacity on inhibition of Saccharomyces cerevisiae growth by acetic and lactic acids. Appl. Environ. Microbiol. 68, 1616-1623.

37. Wheeler, T. L., Crouse, J. D., and Koohmaraie, M. (1992) The effect of postmortem time of injection and freezing on the effectiveness of calcium chloride for improving beef tenderness. J. Anim. Sci. 70, 3451-3457.
38. Yaganza, E. S., Tweddell, R. J., and Arul, J. (2009) Physicochemical basis for the inhibitory effects of organic and inorganic salts on the growth of Pectobacterium carotovorum subsp. carotovorum and Pectobacterium atrosepticum. Appl. Environ. Microbiol. 75, 1465-1469.

39. Young, L. L. and Lyon, C. E. (1997) Effect of calcium marination on biochemical and textural properties of peri-rigor chicken breast meat. Poultry Sci. 76, 197-201.

$\overline{\text { (Received 2013.12.31/Revised 2014.3.14/Accepted 2014.3.25) }}$ 